Article

\title{
Nonlinear Coupled Dynamics of a Rod Fastening Rotor under Rub-Impact and Initial Permanent Deflection
}

\author{
Liang $\mathrm{Hu}^{*}$, Yibing Liu *, Wei Teng and Chao Zhou \\ School of Energy, Power and Mechanical Engineering, North China Electric Power University, \\ Beijing 102206, China; tengw@ncepu.edu.cn (W.T.); zhouchao@ncepu.edu.cn (C.T.) \\ * Correspondence: liang_h@ncepu.edu.cn (L.H.); lyb@ncepu.edu.cn (Y.L.); Tel.: +86-10-6177-2252 (Y.L.) \\ Academic Editor: Ying-Yi Hong \\ Received: 22 August 2016; Accepted: 24 October 2016; Published: 28 October 2016
}

\begin{abstract}
A nonlinear coupled dynamic model of a rod fastening rotor under rub-impact and initial permanent deflection was developed in this paper. The governing motion equation was derived by the D'Alembert principle considering the contact characteristic between disks, nonlinear oil-film force, rub-impact force, unbalance mass, etc. The contact effects between disks was modeled as a flexural spring with cubical nonlinear stiffness. The coupled nonlinear dynamic phenomena of the rub-impact rod fastening rotor bearing system with initial permanent deflection were investigated by the fourth-order Runge-Kutta method. Bifurcation diagram, vibration waveform, frequency spectrum, shaft orbit and Poincaré map are used to illustrate the rich diversity of the system response with complicated dynamics. The studies indicate that the coupled dynamic responses of the rod fastening rotor bearing system under rub-impact and initial permanent deflection exhibit a rich nonlinear dynamic diversity, synchronous periodic-1 motion, multiple periodic motion, quasi-periodic motion and chaotic motion can be observed under certain conditions. Larger radial stiffness of the stator will simplify the system motion and make the oil whirl weaker or even disappear at a certain rotating speed. With the increase of initial permanent deflection length, the instability speed of the system gradually rises, and the chaotic motion region gets smaller and smaller. The corresponding results can provide guidance for the fault diagnosis of a rub-impact rod fastening rotor with initial permanent deflection and contribute to the further understanding of the nonlinear dynamic characteristics of the rod fastening rotor bearing system.
\end{abstract}

Keywords: rod fastening rotor; contact; D'Alembert principle; coupled dynamic characteristic; bifurcation; initial permanent deflection

\section{Introduction}

The rotor-stator rub-impact is one of the most typical faults in rotor bearing systems, and it will result in strong vibration and even catastrophic accidents of the machines if not caught quickly. Actually, the clearance between rotor and stator is inevitable in rotating machines. The existing studies indicate that the smaller clearance between rotor and stator will improve the efficiency greatly. For demand of high efficiency, high rotating speed and high power in modern machines, minimizing radial clearance between rotor and stator is designed, which results in an increase of the probability of rotor-stator rub-impact. Meanwhile, the oil-film instability and larger imbalance can also give rise to the occurrence of rotor-stator rub-impact. The rotor-stator rub-impact can induce the severe vibration of the machine and lead to the permanent deflection of the shaft. Thus, it is essential to analyze the nonlinear coupled dynamic behavior of the rod fastening rotor under rub-impact and initial permanent deflection. 
During the past few decades, much literature has been reported in the field of failure mechanisms and complicated dynamic response of rub-impact rotor systems. Faulty rotor-stator rub-impact is a typical nonlinear issue. Many nonlinear dynamic phenomena, such as bifurcation, synchronous vibration, sub-synchronous vibration, super-synchronous vibration and chaos motion can be observed in rub-impact rotor bearing systems [1]. Ma et al. [2-4] focused their studies on the nonlinear dynamic response and fault feature extraction of rub-impact rotor bearing systems, the dynamic responses under different rubbing forms were discussed, and some signal analysis methods were developed to recognize the rub-impact fault. Weaver et al. [5] established a three-disk nonlinear rotor dynamic model due to the unbalanced driven rub, and proposed a method to solving rub-impact problems by adjusting a combination of bearing parameters. For occasional and partial rubbing forms, Goldman et al. [6] established the model of a rotor/stator system with external excitation and studied the chaotic dynamic behavior of the system. Xiang et al. [7] modeled an asymmetric double-disc rotor-bearing system under rub-impact and oil-film forces and studied the coupled nonlinear dynamics of the system. Wang et al. [8] investigated the dynamic response of rotor systems with sudden unbalance and rub-impact caused by blade loss using theoretical and experimental methods. Generally, the rub-impact rotor bearing system is assumed with symmetric support stiffness, and the asymmetric support is not considered in the dynamic model. For the first time, Varney et al. [9] emphasized the influence of asymmetric support stiffness on the nonlinear dynamic behaviors of the rub-impact rotor bearing system. Tai et al. [10] modeled a single rub-impact rotor system considering the gyroscopic effect, and analyzed the stability and steady-state response of the rotor system. The rotor orbits can reflect the faults of rotor bearing systems to a certain extent. Many researchers have paid attention to the fault classification of rotating machines using the rotor orbits method. Nembhard et al. [11,12] did some experimental observations in the shaft orbits with different rotor related faults and applied them to the fault classification of rotating machines.

The studies on the rub-impact rotor system mainly focus on the lateral vibration characteristics. The effect of rub-impact between rotor and stator on the torsional vibration of the rotor system is often neglected. Edwards et al. [13] highlighted the importance of considering the torsional effects in the rub-impact model and discussed the influence of rub-impact between rotor and stator on torsional responses of the system. Sun et al. [14] modeled a bending-torsional coupling rub-impact rotor system and analyzed the nonlinear dynamic characteristics of the system. The existence of fiction force during rotor-stator rub-impact will generate the coupled effect on lateral and torsional motion. Khanlo et al. [15] modeled a mathematical model of a rotating flexible shaft-disk system considering the lateral-torsional coupling effects. The rotor system with rotor-stator rub-impact and fatigue crack of the shafts displays strong nonlinearity, and Patel et al. [16] developed a coupled bending-torsional dynamic model of a rotor with rub-impact and crack. Hilbert-Huang transform was evaluated as an effective method to unravel some unique features of these faults that may be useful for fault identification. Yuan et al. [17] established a full-degree-of-freedom model of Jeffcott rotor with a rotor's axial rub-impact. The results indicated that the dynamic responses were quite different from those of radial ones. Meanwhile, the bending-torsion coupling phenomenon was disclosed.

For the rotor system, manufacture deviation, unfitting assembly, misalignment and thermal bending can result in the residual shaft bow. Nicholas et al. [18] carried out a systematic study on the effect of the residual shaft bow on unbalance response of a single mass flexible rotor. Song et al. [19] presented a theoretical-experimental study on the dynamic response of a rotor with the residual shaft bow. The results indicated that the residual shaft bow can obviously affect the rotor vibration as the eccentricity and the damping ratio are relatively small. Darpe et al. [20] formulated the motion equations of a bowed rotor with a transverse surface crack and investigated the steady state and transient response. Flack and Rooke [21] compared the theoretical and experimental synchronous unbalanced response of a Jeffcott rotor with a bow on different types of fluid film bearings using the transfer matrix method.

The research above concentrated on the integral rotor bearing system instead of the rod fastening rotor. The rod fastening rotors have been widely applied in the gas turbine and aero-engines for 
the advantages of being light weight, strong and being easy to cool. The effect of rod pre-tightening force on the critical speeds of a rod fastening rotor was studied through experimental methods [22]. The experimental results were in accordance with theoretical analysis results. The nonlinear flexural stiffness of the contact interfaces in disks affects the dynamic response of the rod fastening rotor directly, and Yuan et al. [23] calculated the contact stiffness using the finite element method, and the harmonic balance method was adopted to analyze the dynamic behavior of the rotor system. The dynamic responses of laminated rotor are potentially different from the integral rotor, and Mat Isa et al. [24] developed the model of a laminated rotor and designed a test-rig of laminated rotor to verify the numerical results. Hei et al. $[25,26]$ modeled the rod and contact surfaces of disks as resistance bending springs with nonlinearity, and then investigated the nonlinear dynamic response of a rod fastening rotor bearing system. For a particular aero-engine, the high pressure rotor dynamic response presented an obvious bistable characteristic when equipped. Cheng et al. $[27,28]$ established a dynamic model of the aero-engine rod fastening rotor, and the response was calculated using the harmonic balance method. Under certain system parameters, the bistable response phenomenon could be observed, and the nonlinear contact stiffness was the main factor causing the bistable characteristic.

For the existing work, some researchers paid attention to studies on the contact stiffness, and natural characteristics of the rod fastening rotor. The studies about the dynamic response of a rod fastening rotors under certain fault conditions are rarely reported in literature. Some attempts are presented in this paper to understand the coupled nonlinear dynamic characteristics of a rub-impact rod fastening under rub-impact and initial permanent deflection. The nonlinear contact characteristic between disks is modeled as a flexural spring with nonlinear stiffness. The effect of rotating speed, radial stiffness of the stator, initial deflection and eccentric mass on the dynamic response of the rod fastening rotor bearing system are studied using fourth-order Runge-Kutta method.

\section{Modeling of a Rub-Impact Rod Fastening Rotor System}

A schematic of a rub-impact rod fastening rotor bearing system with initial permanent deflection is shown in Figure 1. The lumped mass in journal bearings are $m_{\mathrm{b} 1}$ and $m_{\mathrm{b} 2}, m_{1}$ and $m_{2}$ are the lumped mass of two disks, $e_{1}$ and $e_{2}$ are the eccentric distance of two disks, and $\phi$ is the angle between unbalance mass of the two disks. The stiffness of shaft is $k, c_{1}$ and $c_{2}$ are the damping coefficient in the journal bearing and disks, and the damping coefficient in contact layer is $c_{3}, \delta_{0}$ is initial deflection. The dynamic model of the rod fastening rotor under rub-impact and initial permanent deflection is simplified with following assumptions: (1) the effects of rods and contacts on the system response are modeled as a flexural spring with nonlinear stiffness; (2) the shaft connecting the bearing and disk is flexible massless, and only lateral vibration is considered in the model; (3) the rod fastening rotor is supported by identical oil-film bearings at both sides, and the nonlinear oil-film force of the journal bearing is satisfied with the theory of short bearing; and (4) the rub-impact between disk 1 and stator is elastic, the radial deformation is elastic deformation, and the tangential friction force meets the Coulomb friction law.

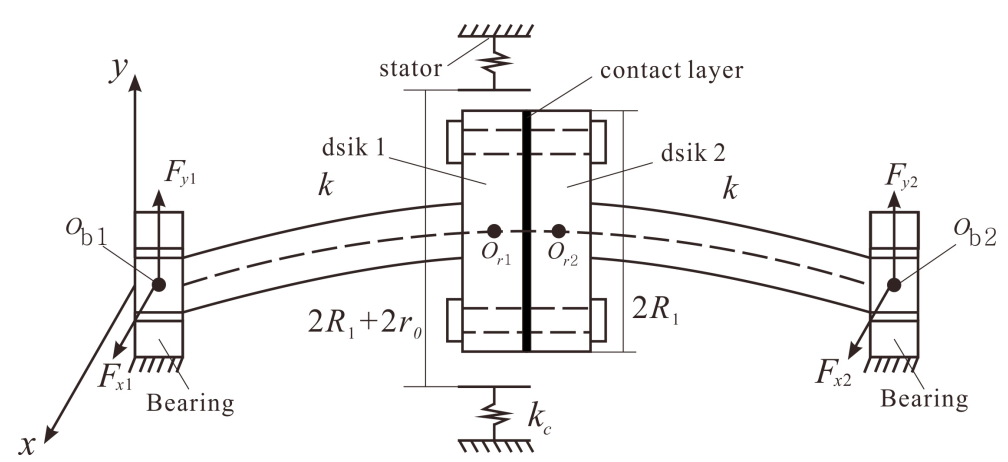

Figure 1. Schematic of a rub-impact rod fastening rotor with initial permanent deflection. 


\subsection{Rub-Impact Force}

Figure 2 is the schematic of a rub-impact forces model with an initial clearance $r_{0}$ between disk 1 and stator. $O_{\mathrm{s}}$ is the stator center, $O_{r 1}{ }^{\prime}$ is the geometric center of disk $1, O_{r 1}$ is the initial geometric center of disk 1 .

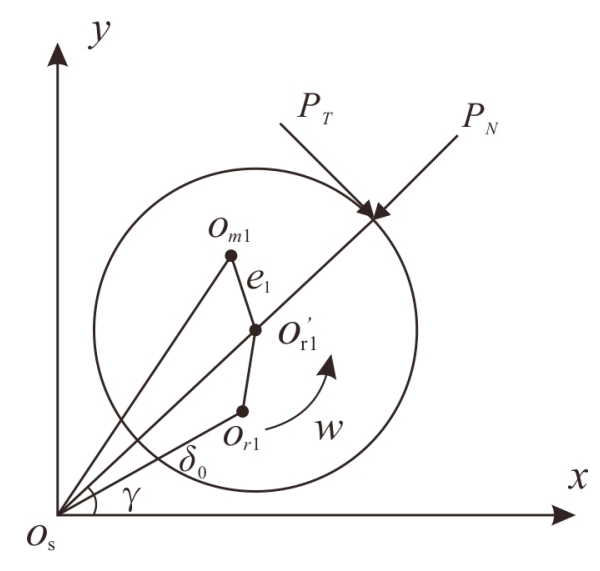

Figure 2. Schematic of rub-impact forces.

The radial impact force $P_{N}$ can be expressed following linear elastic deformation theory. The tangential rub force $P_{T}$ can be represented following Coulomb law [9]:

$$
\left\{\begin{array}{c}
P_{N}=k_{c}\left(r-r_{0}\right) \\
P_{T}=\eta P_{N}
\end{array} \quad\left(r \geq r_{0}\right),\right.
$$

where $r$ is the radial displacement of the disk $1, r=\sqrt{x_{1}^{2}+y_{1}^{2}}, k_{c}$ is the radial stiffness of the stator, and $\eta$ is the friction coefficient.

The radial impact force $P_{N}$ and the tangential rub force $P_{T}$ can be written in $x-y$ coordinates as

$$
\begin{gathered}
\left\{\begin{array}{c}
P_{x} \\
P_{y}
\end{array}\right\}=\left[\begin{array}{cc}
-\cos \gamma & \sin \gamma \\
-\sin \gamma & -\cos \gamma
\end{array}\right]\left\{\begin{array}{c}
P_{N} \\
P_{T}
\end{array}\right\}=-\frac{k_{c}\left(r-r_{0}\right)}{r}\left[\begin{array}{cc}
1 & -\eta \\
\eta & 1
\end{array}\right]\left\{\begin{array}{l}
x_{1} \\
y_{1}
\end{array}\right\} \quad\left(r \geq r_{0}\right) . \\
P_{x}=P_{y}=0 \quad\left(r<r_{0}\right)
\end{gathered}
$$

Taking $X_{1}=x_{1} / c, Y_{1}=y_{1} / c, c$ is radial clearance of the bearing. Equation (2) can be rewritten as:

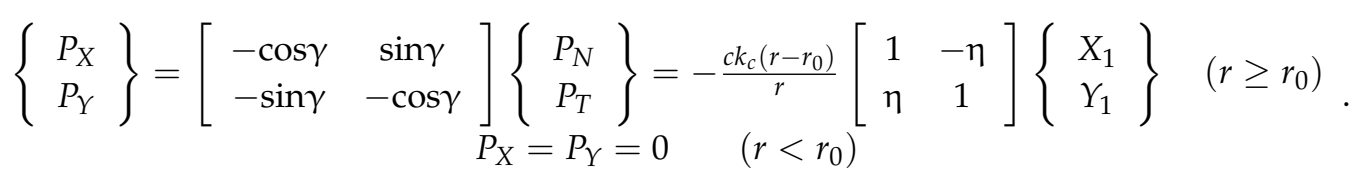

\subsection{Nonlinear Oil-Film Force}

The capone nonlinear oil-film force model [29] has been proved as an effective model in calculating the nonlinear oil-film force. It is assumed that lubricating oil is isothermal, laminar flow and lubricant dynamic viscosity are constant, and lubricating oil is an incompressible fluid. 
The oil-film bearing is shown in Figure 3. According to the Reynolds equation, the dimensionless oil-film pressure distribution is expressed as follows [30]:

$$
\left(\frac{R}{L}\right)^{2} \frac{\partial}{\partial Z}\left(h^{3} \frac{\partial p}{\partial Z}\right)=X \sin \theta-Y \cos \theta-2(\dot{X} \cos \theta+\dot{Y} \sin \theta)
$$

where $X$ and $Y$ are dimensionless displacements of journal bearing center respectively, $X=x / c, Y=y / c$. $Z$ is the dimensionless axial displacement of the journal center, and $c$ is the radial clearance of bearing. $p$ is the dimensionless pressure, $h$ is the thickness of oil-film, $R$ is radius of bearing, and $L$ is the length of the bearing.

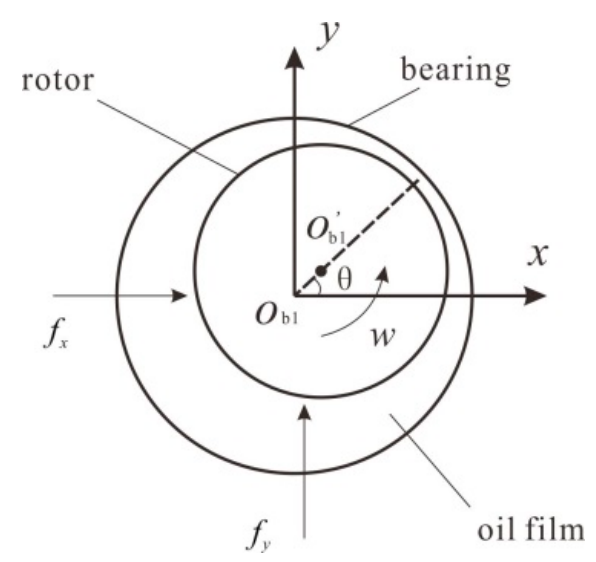

Figure 3. Schematic of oil-film bearing.

The dimensionless pressure $p$ can be obtained by integrating Equation (4):

$$
p=\frac{1}{8}\left(\frac{L}{R}\right)^{2} \frac{(X-2 \dot{Y}) \sin \theta-(Y+2 \dot{X}) \cos \theta}{(1-X \cos \theta-Y \sin \theta)^{3}}\left(4 Z^{2}-1\right) .
$$

The nonlinear oil-film force in the $x$-direction and $y$-direction can be obtained with Equation (5) through integration along the lubricated arc of bearing:

$$
\left\{\begin{array}{l}
f_{x} \\
f_{y}
\end{array}\right\}=\frac{1}{\delta P}\left\{\begin{array}{l}
F_{x} \\
F_{y}
\end{array}\right\}=-\frac{\left[(X-2 \dot{Y})^{2}+(Y+2 \dot{X})^{2}\right]^{1 / 2}}{1-X^{2}-Y^{2}} \times\left\{\begin{array}{l}
3 X \cdot V(X, Y, \alpha)-\sin \alpha \cdot G(X, Y, \alpha)-2 \cos \alpha \cdot S(X, Y, \alpha) \\
3 Y \cdot V(X, Y, \alpha)+\cos \alpha \cdot G(X, Y, \alpha)-2 \sin \alpha \cdot S(X, Y, \alpha)
\end{array}\right\}
$$

where $\delta$ is the Sommerfeld correction coefficient, $\delta=\frac{\mu \omega R L}{P}\left(\frac{R}{c}\right)^{2}\left(\frac{L}{2 R}\right)^{2}, \mu$ is oil viscosity, $\omega$ is the excitation frequency, and $P$ is the half mass of the disk. $V(X, Y, \alpha), S(X, Y, \alpha), G(X, Y, \alpha), \alpha$ are expressed as follows:

$$
\begin{gathered}
V(X, Y, \alpha)=\frac{2+(Y \cos \alpha-X \sin \alpha) G(X, Y, \alpha)}{1-X^{2}-Y^{2}}, \\
S(X, Y, \alpha)=\frac{X \cos \alpha+Y \sin \alpha}{1-(X \cos \alpha+Y \sin \alpha)^{2}}, \\
G(X, Y, \alpha)=\frac{2}{\left(1-X^{2}-Y^{2}\right)^{1 / 2}}\left[\frac{\pi}{2}+\arctan \frac{Y \cos \alpha-X \sin \alpha}{\left(1-X^{2}-Y^{2}\right)^{1 / 2}}\right], \\
\alpha=\arctan \frac{Y+2 \dot{X}}{X-2 \dot{Y}}-\frac{\pi}{2} \operatorname{sign}\left[\frac{Y+2 \dot{X}}{X-2 \dot{Y}}\right]-\frac{\pi}{2} \operatorname{sign}(Y+2 \dot{X}) .
\end{gathered}
$$




\subsection{The Governing Equations of Motion}

According to the D'Alembert principle, the governing motion equations of the rod fastening rotor under rub-impact and initial permanent deflection can be written as:

$$
\left\{\begin{array}{l}
m_{b 1} \ddot{x}_{b 1}+c_{1} \dot{x}_{b 1}+k\left(x_{b 1}-x_{1}\right)=F_{x}\left(x_{b 1}, y_{b 1}, \dot{x}_{b 1}, \dot{y}_{b 1}\right) \\
m_{b 1} \ddot{y}_{b 1}+c_{1} \dot{y}_{b 1}+k\left(y_{b 1}-y_{1}\right)=F_{y}\left(x_{b 1}, y_{b 1}, \dot{x}_{b 1}, \dot{y}_{b 1}\right)-m_{b 1} g \\
m_{1} \ddot{x}_{1}+c_{2} \dot{x}_{1}+c_{3}\left(\dot{x}_{1}-\dot{x}_{2}\right)+k\left(x_{1}-x_{b 1}\right)+F_{c x 1}=m_{1} e_{1} \omega^{2} \cos \omega t+k \delta_{0} \cos (\omega t+\beta)+P_{x} \\
m_{1} \ddot{y}_{1}+c_{2} \dot{y}_{1}+c_{3}\left(\dot{y}_{1}-\dot{y}_{2}\right)+k\left(y_{1}-y_{b 1}\right)+F_{c y 1}=m_{1} e_{1} \omega^{2} \sin \omega t+k \delta_{0} \sin (\omega t+\beta)-m_{1} g+P_{y} \\
m_{2} \ddot{x}_{2}+c_{2} \dot{x}_{2}+c_{3}\left(\dot{x}_{2}-\dot{x}_{1}\right)+k\left(x_{2}-x_{b 2}\right)+F_{c x 2}=m_{2} e_{2} \omega^{2} \cos (\omega t+\phi)+k \delta_{0} \cos (\omega t+\beta) \\
m_{2} \ddot{y}_{2}+c_{2} \dot{y}_{2}+c_{3}\left(\dot{y}_{2}-\dot{y}_{1}\right)+k\left(y_{2}-y_{b 2}\right)+F_{c y 2}=m_{2} e_{2} \omega^{2} \sin (\omega t+\phi)+k \delta_{0} \sin (\omega t+\beta)-m_{2} g \\
m_{b 2} \ddot{x}_{b 2}+c_{1} \dot{x}_{b 2}+k\left(x_{b 2}-x_{2}\right)=F_{x}\left(x_{b 2}, y_{b 2}, \dot{x}_{b 2}, \dot{y}_{b 2}\right) \\
m_{b 2} \ddot{y}_{b 2}+c_{1} \dot{y}_{b 2}+k\left(y_{b 2}-y_{2}\right)=F_{y}\left(x_{b 2}, y_{b 2}, \dot{x}_{b 2}, \dot{y}_{b 2}\right)-m_{b 2} g
\end{array},\right.
$$

where $F_{x}$ and $F_{y}$ are the nonlinear oil-film force in the $x$-direction and $y$-direction, $P_{x}$ and $P_{y}$ are the rub-impact force in the $x$-direction and $y$-direction, $\phi$ is the angle between mass eccentricity of the two disks, and $\beta$ is the phase angle between the mass eccentricity and the initial permanent deflection. $F_{c x 1}$, $F_{c y 1}, F_{c x 2}, F_{c y 2}$ are the nonlinear restoring forces of contact layer, the expressions are as the following:

$$
\left\{\begin{array}{l}
F_{c x 1}=-F_{c x 2}=k_{1}\left(x_{1}-x_{2}\right)+k_{1}^{\prime}\left(x_{1}-x_{2}\right)^{3} \\
F_{c y 1}=-F_{c y 2}=k_{1}\left(y_{1}-y_{2}\right)+k_{1}^{\prime}\left(y_{1}-y_{2}\right)^{3}
\end{array},\right.
$$

where $k_{1}$ is the linear contact stiffness, and $k_{1}{ }^{\prime}$ is the nonlinear contact stiffness.

Substituting the dimensionless oil-film force and rub-impact force into Equation (11), the dimensionless motion equation of the system can be obtained:

$$
\left\{\begin{array}{l}
\ddot{X}_{b 1}+\frac{c_{1}}{m_{b 1} \omega} \dot{X}_{b 1}+\frac{k}{m_{b 1} \omega^{2}}\left(X_{b 1}-X_{1}\right)=\frac{\delta P}{m_{b 1} c \omega^{2}} f_{x}\left(X_{b 1}, Y_{b 1}, \dot{X}_{b 1}, \dot{Y}_{b 1}\right) \\
\ddot{Y}_{b 1}+\frac{c_{1}}{m_{b 1} \omega} \dot{Y}_{b 1}+\frac{k}{m_{b 1} \omega^{2}}\left(Y_{b 1}-Y_{1}\right)=\frac{\delta P}{m_{b 1} c \omega^{2}} f_{y}\left(X_{b 1}, Y_{b 1}, \dot{X}_{b 1}, \dot{Y}_{b 1}\right)-\frac{g}{c \omega^{2}} \\
\ddot{X}_{1}+\frac{c_{2}}{m_{1} \omega} \dot{X}_{1}+\frac{c_{3}}{m_{1} \omega}\left(\dot{X}_{1}-\dot{X}_{2}\right)+\frac{k}{m_{1} \omega^{2}}\left(X_{1}-X_{b 1}\right)+\frac{F_{c x 1}}{m_{1} c \omega^{2}}=\frac{e_{1}}{c} \cos (\tau)+\frac{k \delta_{0}}{m_{1} c \omega^{2}} \cos (\tau+\beta)+\frac{P_{X}}{m_{1} c \omega^{2}} \\
\ddot{Y}_{1}+\frac{c_{2}}{m_{1} \omega} \dot{Y}_{1}+\frac{c_{3}}{m_{1} \omega}\left(\dot{Y}_{1}-\dot{Y}_{2}\right)+\frac{k}{m_{1} \omega^{2}}\left(Y_{1}-Y_{b 1}\right)+\frac{F_{c y 1}}{m_{1} c \omega^{2}}=\frac{e_{1}}{c} \sin (\tau)+\frac{k \delta_{0}}{m_{1} c \omega^{2}} \sin (\tau+\beta)-\frac{g}{c \omega^{2}}+\frac{P_{Y}}{m_{1} c \omega^{2}} \\
\ddot{X}_{2}+\frac{c 2}{m_{2} \omega} \dot{X}_{2}+\frac{c}{m_{2} \omega}\left(\dot{X}_{2}-\dot{X}_{1}\right)+\frac{k}{m_{2} \omega^{2}}\left(X_{2}-X_{b 2}\right)+\frac{F_{c x 2}}{m_{2} c \omega^{2}}=\frac{e_{2}}{c} \cos (\tau+\phi)+\frac{k \delta_{0}}{m_{2} c \omega^{2}} \cos (\tau+\beta) \\
\ddot{Y}_{2}+\frac{c_{2}}{m_{2} \omega} \dot{Y}_{2}+\frac{c_{3}}{m_{2} \omega}\left(\dot{Y}_{2}-\dot{Y}_{1}\right)+\frac{k}{m_{2} \omega^{2}}\left(Y_{2}-Y_{b 2}\right)+\frac{F_{c y 2}}{m_{2} c \omega^{2}}=\frac{e_{2}}{c} \sin (\tau+\phi)+\frac{k \delta_{0}}{m_{2} c \omega^{2}} \sin (\tau+\beta)-\frac{g}{c \omega^{2}} \\
\ddot{X}_{b 2}+\frac{c 1}{m_{b 2} \omega} \dot{X}_{b 2}+\frac{k}{m_{b 2} \omega^{2}}\left(X_{b 2}-X_{2}\right)=\frac{\delta P}{m_{b 2} c \omega^{2}} f_{x}\left(X_{b 2}, Y_{b 2}, \dot{X}_{b 2}, \dot{Y}_{b 2}\right) \\
\ddot{Y}_{b 2}+\frac{c_{1}}{m_{b 2} \omega} \dot{Y}_{b 2}+\frac{k}{m_{b 2} \omega^{2}}\left(Y_{b 2}-Y_{2}\right)=\frac{\delta P}{m_{b 2} c \omega^{2}} f_{y}\left(X_{b 2}, Y_{b 2}, \dot{X}_{b 2}, \dot{Y}_{b 2}\right)-\frac{g}{c \omega^{2}}
\end{array}\right.
$$

where $\tau$ is dimensionless time, $\tau=\omega t, X_{b 1}=x_{b 1} / c, X_{b 2}=x_{b 2} / c, Y_{b 1}=y_{b 1} / c, Y_{b 2}=y_{b 2} / c, X_{1}=x_{1} / c$, $X_{2}=x_{2} / c, Y_{1}=y_{1} / c$, and $Y_{2}=y_{2} / c$.

\section{Numerical Results and Discussion}

The parameters of the rod fastening rotor system are: $m_{b 1}=4 \mathrm{~kg}, m_{b 2}=4 \mathrm{~kg}, m_{1}=32.1 \mathrm{~kg}$, $m_{2}=32.1 \mathrm{~kg}, c_{1}=1050 \mathrm{~N} \cdot \mathrm{s} / \mathrm{m}, c_{2}=2100 \mathrm{~N} \cdot \mathrm{s} / \mathrm{m}, c_{3}=2100 \mathrm{~N} \cdot \mathrm{s} / \mathrm{m}, k=2.5 \times 10^{7} \mathrm{~N} / \mathrm{m}$, $k_{1}=2.5 \times 10^{7} \mathrm{~N} / \mathrm{m}, k_{1}{ }^{\prime}=2.5 \times 10^{7} \mathrm{~N} / \mathrm{m}, k_{c}=1 \times 10^{7} \mathrm{~N} / \mathrm{m}, r_{0}=0.18 \mathrm{~mm}, e_{1}=0.05 \mathrm{~mm}, e_{2}=0.05 \mathrm{~mm}$, $\delta_{0}=0.01 \mathrm{~mm}, \beta=\pi / 4, \eta=0.1, \phi=0, R=25 \mathrm{~mm}, L=12 \mathrm{~mm}, c=0.11 \mathrm{~mm}, \mu=0.018 \mathrm{~Pa} \cdot \mathrm{s}$, and $g=9.81 \mathrm{~m} / \mathrm{s}^{2}$. Assuming that the rod fastening rotor has rigid support, the natural frequency $\omega_{\mathrm{c}}=\left(k / m_{1}\right)^{1 / 2}=882 \mathrm{rad} / \mathrm{s}$. In fact, the rotor cannot have complete rigid support, and the critical speed should be less than $882 \mathrm{rad} / \mathrm{s}$. The coupled nonlinear dynamic analysis of a rod fastening rotor under rub-impact and initial permanent deflection is carried out by the fourth-order Runge-Kutta method. The period of the dimensionless system is $2 \pi$; the integral step length of each period is $1 / 100$; the calculation is 200 periods; we choose the last 100 periods as the effective analysis data; and the number 
of the effective data points is 10,000. Bifurcation diagram, vibration waveform, frequency spectrum, shaft orbit and Poincaré map are presented to illustrate the nonlinear dynamic phenomena of system as follows.

\subsection{Effect of Speed}

The dynamic responses and system status vary with the increase of rotating speed. Bifurcation diagram can clearly reflect the relationship of the system status varying with parameters.

Taking rotating speed as control parameter, Figure 4 shows the bifurcation diagram of an integral rotor bearing system in a horizontal direction of disk center without considering the initial permanent deflection and contact characteristics between disks. The system keeps synchronous period-1 motion at $\omega<507 \mathrm{rad} / \mathrm{s}$. With the increasing of rotating speed, the system response exhibits a rich nonlinear dynamic diversity.

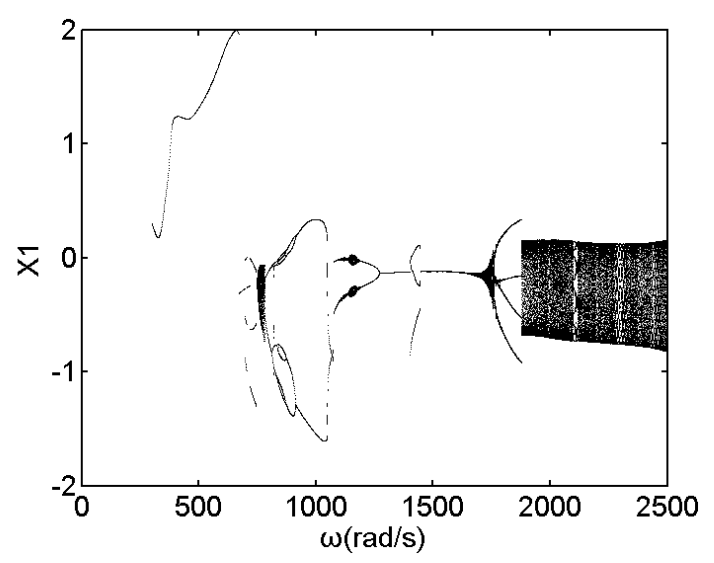

Figure 4. Bifurcation diagram of integral rotor disk center in the $x$-direction at $k_{c}=1 \times 10^{7} \mathrm{~N} / \mathrm{m}, \delta_{0}=0$.

Figure 5 shows the bifurcation diagram of a rub-impact rod fastening rotor bearing system at $\delta_{0}=0, k_{c}=1 \times 10^{7} \mathrm{~N} / \mathrm{m}$. The system response has a big difference in high rotating speed compared with Figure 4 . When $\omega<507 \mathrm{rad} / \mathrm{s}$, the system state is synchronous periodic-1 motion. It can be seen from Figure 6 that there is one isolated point in the Poincare map and one-peak amplitude in the frequency spectrum, and the rub-impact does not occur under this condition. The system turns into periodic- 2 motion at $\omega=507 \mathrm{rad} / \mathrm{s}$. With the increase of rotating speed, the period doubling bifurcation occurs. The periodic- 2 motion, periodic- 4 motion, periodic- 8 motion and chaotic motion are observed one by one. Figure 7 shows the periodic -4 motion at $\omega=670 \mathrm{rad} / \mathrm{s}$, the Poincare map contains four isolated points, the amplitude of half fundamental frequency exceeds the amplitude of fundamental frequency, and the oil whirl occurs at this rotating speed. When $\omega>810 \mathrm{rad} / \mathrm{s}$, inverse period doubling bifurcation occurs. The quasi-periodic motion can be observed at the interval of $1038 \mathrm{rad} / \mathrm{s}<\omega<1615 \mathrm{rad} / \mathrm{s}$, as shown in Figure 8, the Poincaré map of the system presents a closed loop, and the frequency spectrum contains incommensurate frequency components. Meanwhile, the oil whip frequency is less than half of the fundamental frequency, and the amplitude of oil whip frequency is bigger than the amplitude of fundamental frequency. The oil whirl develops into oil whip at this speed, and the shaft orbit exceeds rubbing boundary. When $\omega>1615 \mathrm{rad} / \mathrm{s}$, the system experiences periodic-3 motion, and with the increase of rotating speed, the system finally enters into quasi-periodic motion. Figure 9 shows the periodic- 3 motion at $\omega=1750 \mathrm{rad} / \mathrm{s}$, and the Poincare map performs three isolated points. 


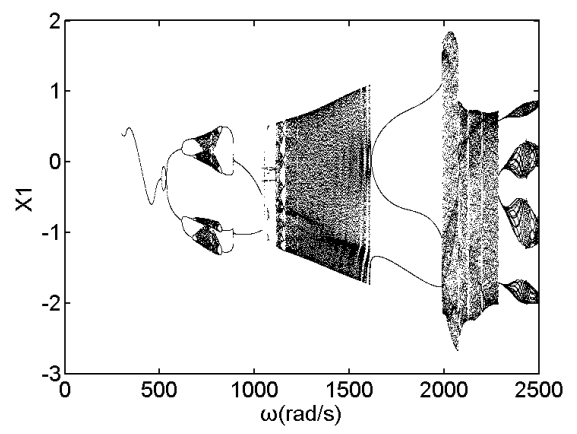

Figure 5. Bifurcation diagram of rod fastening rotor disk 1 center in the $x$-direction at $k_{c}=1 \times 10^{7} \mathrm{~N} / \mathrm{m}$, $\delta_{0}=0$.

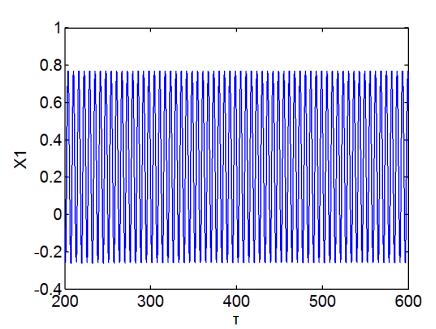

(a)

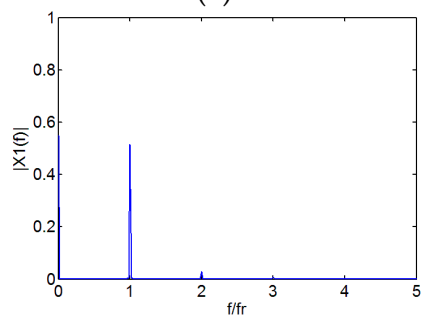

(c)

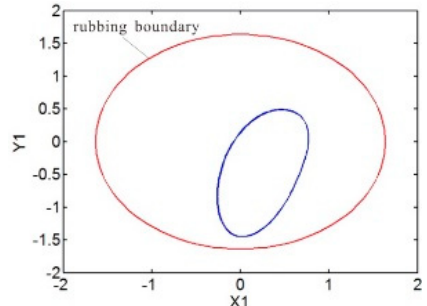

(b)

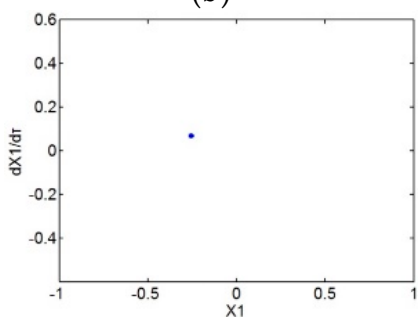

(d)

Figure 6. Numerical analysis results at $\omega=500 \mathrm{rad} / \mathrm{s}, \delta_{0}=0 \mathrm{~mm}$. (a) Time domain waveform; (b) Shaft orbit; (c) Frequency spectrum; (d) Poincaré map.

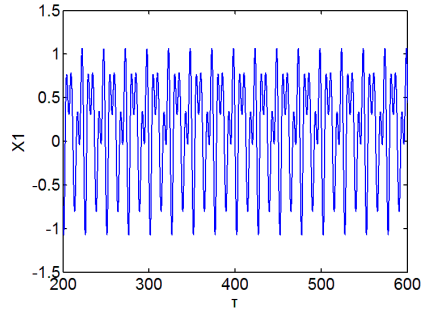

(a)

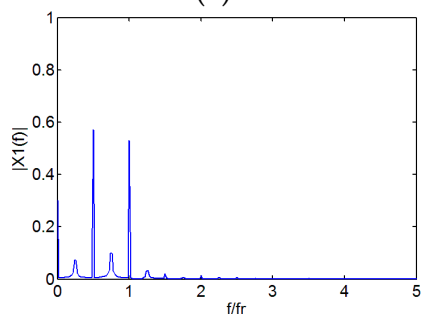

(c)

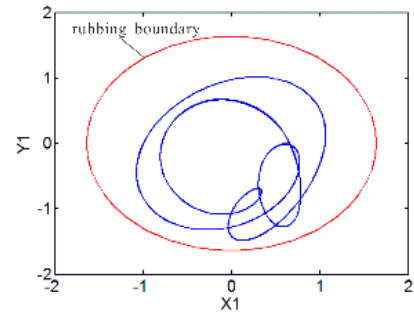

(b)

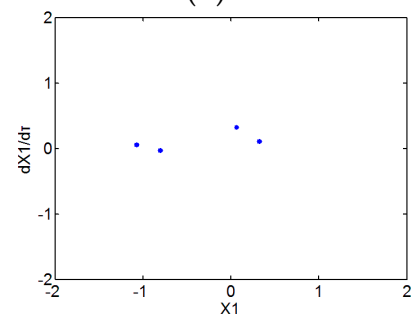

(d)

Figure 7. Numerical analysis results at $\omega=670 \mathrm{rad} / \mathrm{s}, \delta_{0}=0 \mathrm{~mm}$. (a) Time domain waveform; (b) Shaft orbit; (c) Frequency spectrum; (d) Poincaré map. 


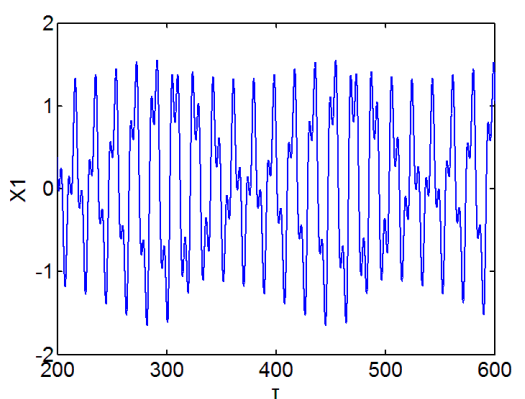

(a)

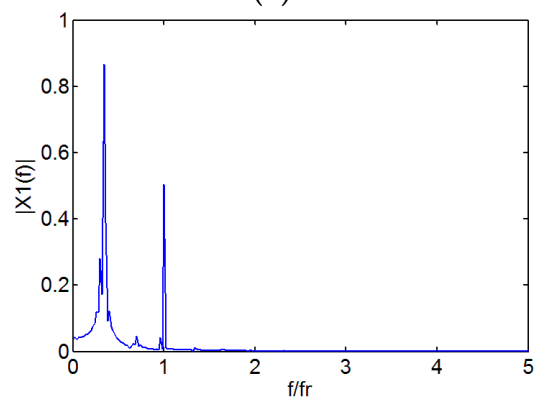

(c)

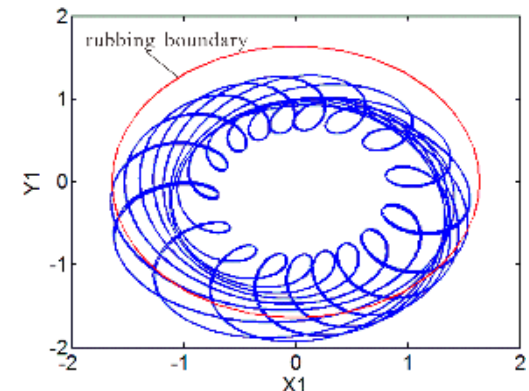

(b)

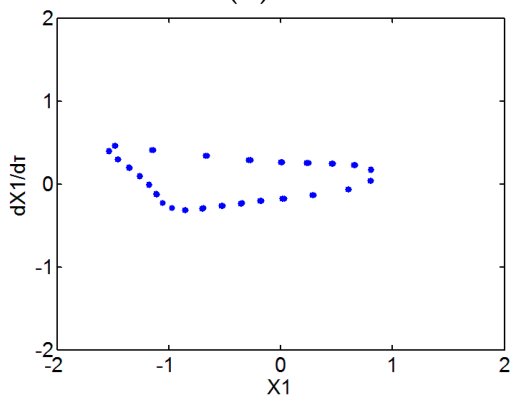

(d)

Figure 8. Numerical analysis results at $\omega=1400 \mathrm{rad} / \mathrm{s}, \delta_{0}=0 \mathrm{~mm}$. (a) Time domain waveform; (b) Shaft orbit; (c) Frequency spectrum; (d) Poincaré map.

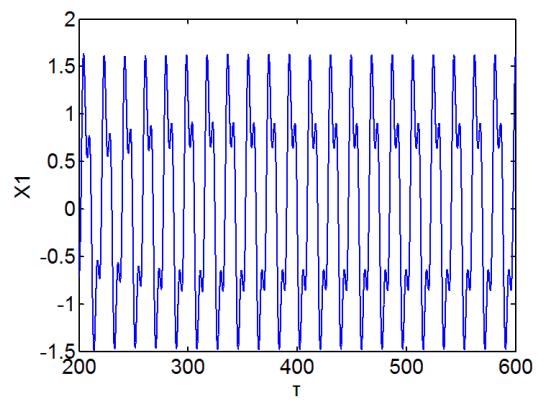

(a)

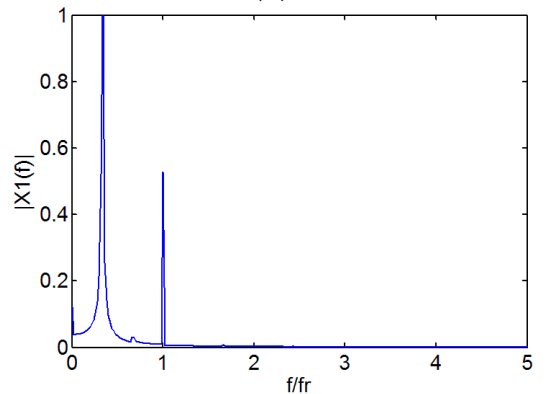

(c)

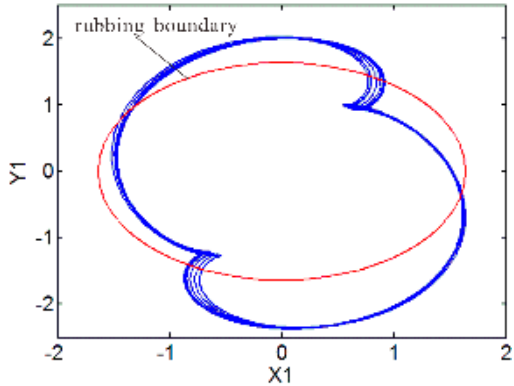

(b)

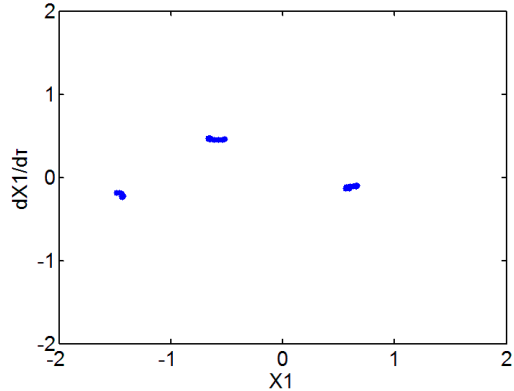

(d)

Figure 9. Numerical analysis results at $\omega=1750 \mathrm{rad} / \mathrm{s}, \delta_{0}=0 \mathrm{~mm}$. (a) Time domain waveform; (b) Shaft orbit; (c) Frequency spectrum; (d) Poincaré map.

The initial permanent deflection is common among rotor systems. In order to analyze the effect of initial permanent deflection on responses of the rub-impact rod fastening rotor bearing system, the study is carried out by setting $\delta_{0}=0.01 \mathrm{~mm}, \beta=\pi / 4$. Figure 10 shows the bifurcation diagram of a disk 1 center in a horizontal direction considering the initial permanent deflection in the system motion equations. 


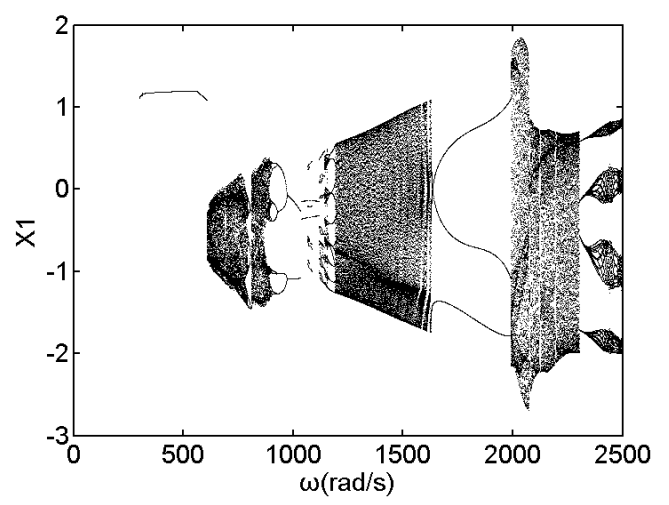

Figure 10. Bifurcation diagram of disk 1 center in a horizontal direction at $k_{c}=1 \times 10^{7} \mathrm{~N} / \mathrm{m}$, $\delta_{0}=0.01 \mathrm{~mm}$.

Similar to the system response without considering the initial permanent deflection, the system presents a synchronous periodic-1 motion at $\omega<608 \mathrm{rad} / \mathrm{s}$ (see Figure 11). Compared with Figure 6, shaft orbit exceeds rubbing boundary, and the rub-impact has occurred already at this rotating speed. Under the effect of initial permanent deflection, unbalance force, oil-film force and rub-impact force, the system directly enters into chaotic motion at $\omega=608 \mathrm{rad} / \mathrm{s}$. As indicated in Figure 12, the frequency spectrum contains continuous frequency bands, the orbit is irregular, and the Poincare map presents a strange attractor. When the rotating speed reaches $898 \mathrm{rad} / \mathrm{s}$, the system leaves chaotic motion and undergoes an inverse period doubling bifurcation. Periodic- 16 motion, periodic- 8 motion, periodic- 4 motion and periodic-2 motion occur alternately at the interval of $608 \mathrm{rad} / \mathrm{s}<\omega<1035 \mathrm{rad} / \mathrm{s}$. With the increase of the rotating speed, the system experiences a transient multi-periodic motion and then enters into quasi-periodic motion. The quasi-periodic motion is illustrated in Figure 13, the Poincare map of the system presents a closed loop, the frequency spectrum is continuous, and the shaft orbit is irregular. At $\omega=1639 \mathrm{rad} / \mathrm{s}$, the system bifurcates into periodic-3 motion (see in Figure 14).

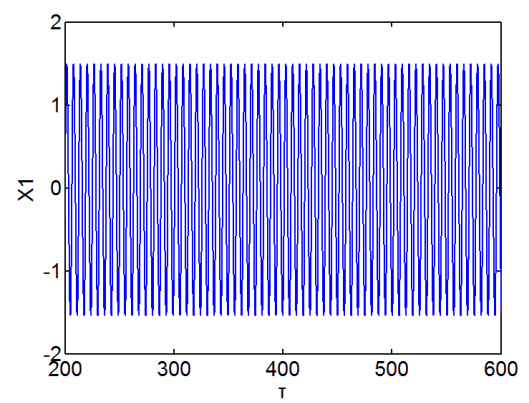

(a)

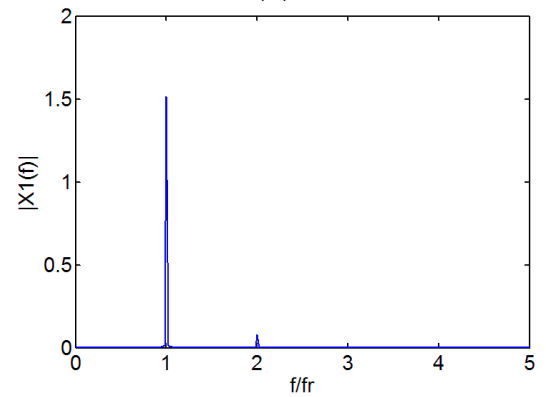

(c)

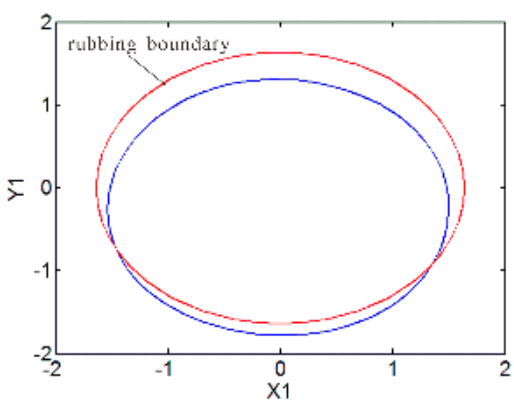

(b)

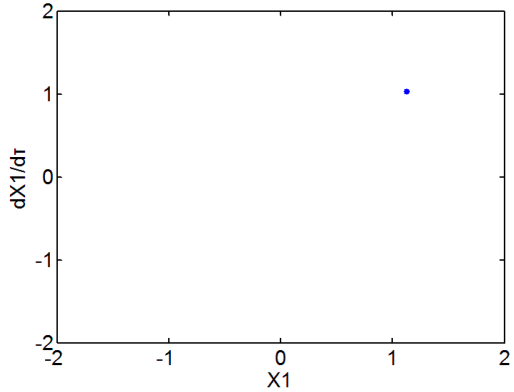

(d)

Figure 11. Numerical analysis results at $\omega=500 \mathrm{rad} / \mathrm{s}, \delta_{0}=0.01 \mathrm{~mm}$. (a) Time domain waveform; (b) Shaft orbit; (c) Frequency spectrum; (d) Poincaré map. 


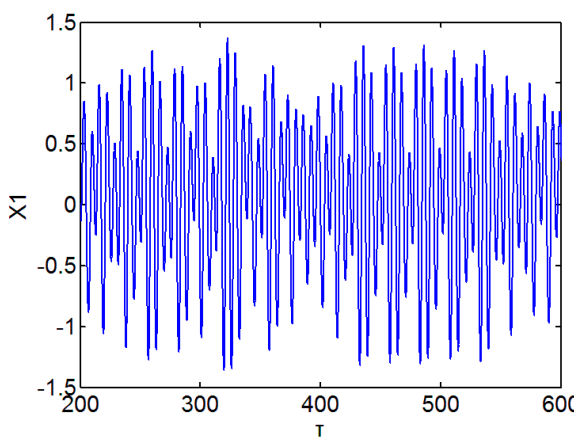

(a)

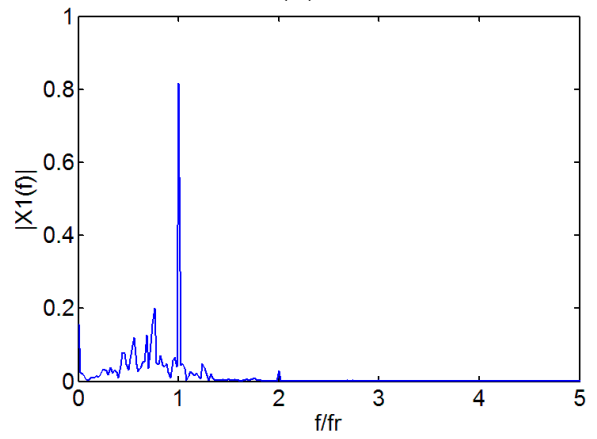

(c)

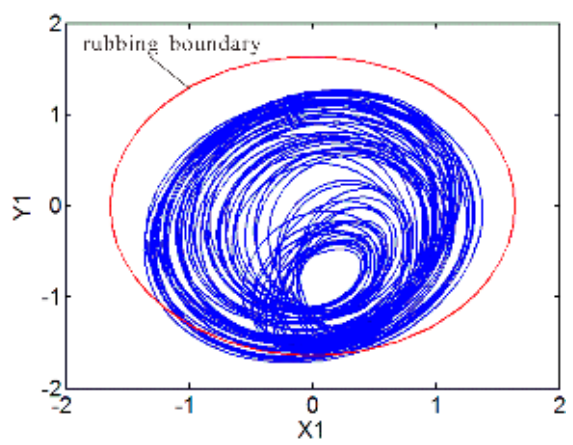

(b)

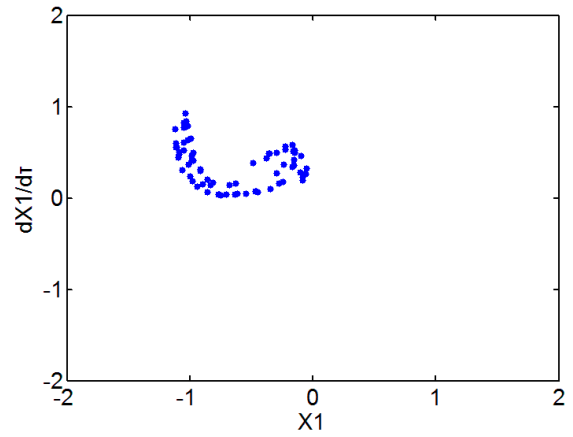

(d)

Figure 12. Numerical analysis results at $\omega=670 \mathrm{rad} / \mathrm{s}, \delta_{0}=0.01 \mathrm{~mm}$. (a) Time domain waveform; (b) Shaft orbit; (c) Frequency spectrum; (d) Poincaré map.

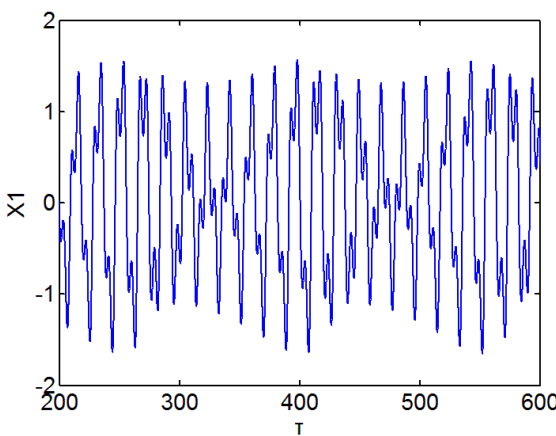

(a)

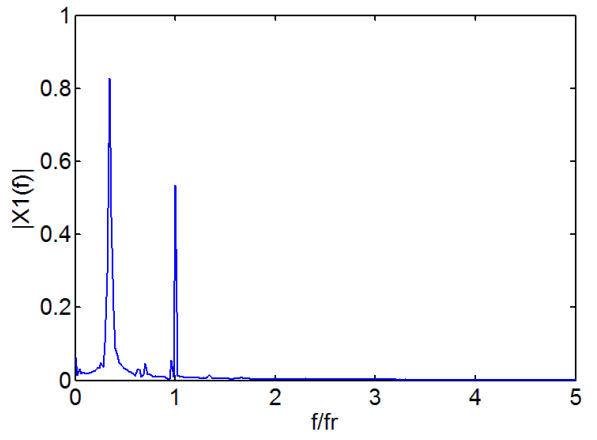

(c)

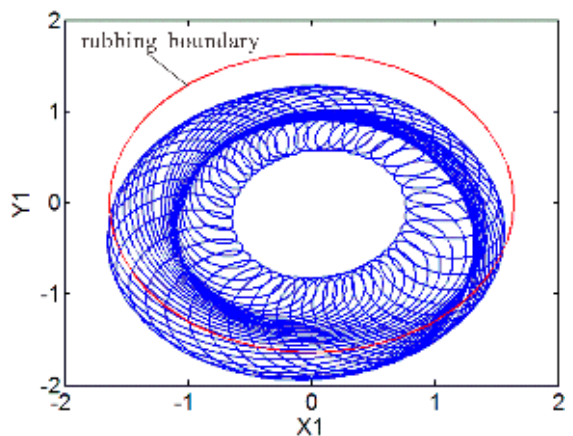

(b)

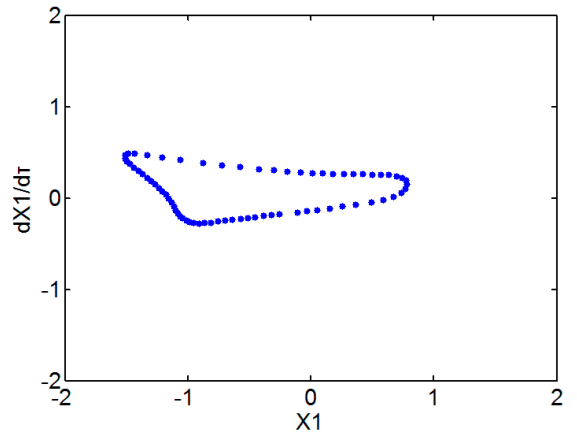

(d)

Figure 13. Numerical analysis results at $\omega=1400 \mathrm{rad} / \mathrm{s}, \delta_{0}=0.01 \mathrm{~mm}$. (a) Time domain waveform; (b) Shaft orbit; (c) Frequency spectrum; (d) Poincaré map. 


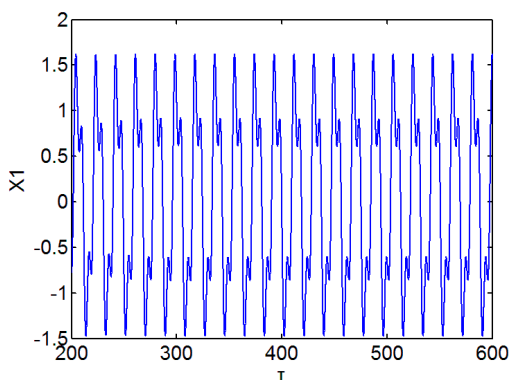

(a)

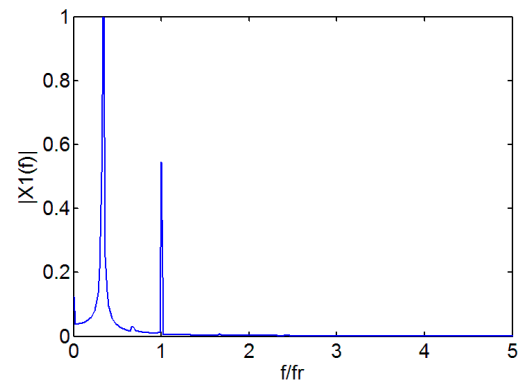

(c)

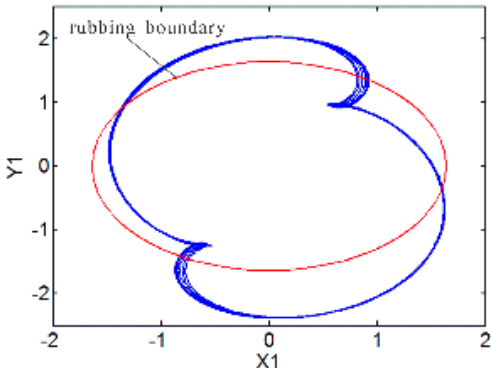

(b)

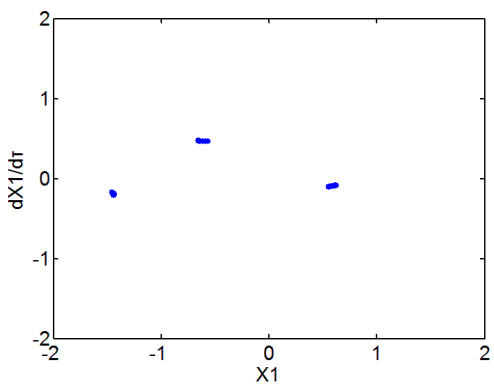

(d)

Figure 14. Numerical analysis results at $\omega=1750 \mathrm{rad} / \mathrm{s}, \delta_{0}=0.01 \mathrm{~mm}$. (a) Time domain waveform; (b) Shaft orbit; (c) Frequency spectrum; (d) Poincaré map.

The bifurcation diagram can reveal the motion state of the system varying with rotating speed. It can be concluded from the above analysis that initial permanent deflection has a great influence on the dynamic response of the rub-impact rod fastening rotor bearing system. Comparing Figure 5 with Figure 10, it is obvious that the initial permanent deflection mainly affects the system response at low speed. The oil-film force and unbalance force are small when the system is at a low speed, and initial permanent deflection becomes the main factor affecting the system states. With the increase of rotating speed, the oil-film force and unbalance force gradually increase and begin to play a leading role in the system states. Meanwhile, the rub-impact occurs at a lower speed when initial permanent deflection is considered.

\subsection{Effect of Initial Permanent Deflection}

The manufacture deviation, unfitting assembly, misalignment and thermal bending can result in the residual shaft bow. In Section 3.1, the results indicate that the initial permanent deflection has a big influence on the system responses. In this part, the effect of different initial permanent deflection length on the dynamic responses of the rub-impact rod fastening rotor bearing system has been discussed.

Taking $k_{c}=1 \times 10^{7} \mathrm{~N} / \mathrm{m}, r_{0}=0.18 \mathrm{~mm}, e_{1}=0.05 \mathrm{~mm}, e_{2}=0.05 \mathrm{~mm}$, and $\beta=\pi / 4$, Figure 15 shows the bifurcation diagrams of the disk 1 center in a horizontal direction under different initial permanent deflection lengths $\delta_{0}=0.01 \mathrm{~mm}, \delta_{0}=0.02 \mathrm{~mm}, \delta_{0}=0.03 \mathrm{~mm}$, and $\delta_{0}=0.04 \mathrm{~mm}$. As shown in Figure $15 \mathrm{a}$, the system bifurcates into chaotic motion at $\omega=608 \mathrm{rad} / \mathrm{s}$ and leaves chaotic motion at $\omega=898 \mathrm{rad} / \mathrm{s}$, with the increase of rotating speed, the system undergoes an inverse period doubling bifurcation. At the interval of $1639 \mathrm{rad} / \mathrm{s}<\omega<1991 \mathrm{rad} / \mathrm{s}$, the system keeps periodic-3 motion. When $\delta_{0}=0.02 \mathrm{~mm}$, the system enters into chaotic motion at $\omega=716 \mathrm{rad} / \mathrm{s}$ and leaves chaotic motion at $\omega=936 \mathrm{rad} / \mathrm{s}$, similar to the bifurcation diagram at $\delta_{0}=0.01 \mathrm{~mm}$, with the increase of rotating speed, the system experiences periodic- 16 motion,periodic- 8 motion,periodic -4 motion,periodic- 2 motion, quasi-periodic motion and keeps periodic-3 motion at $1655 \mathrm{rad} / \mathrm{s}<\omega<1992 \mathrm{rad} / \mathrm{s}$. Figure 15c shows the bifurcation diagram at $\delta_{0}=0.03 \mathrm{~mm}$, and the system bifurcates into chaotic at $\omega=782 \mathrm{rad} / \mathrm{s}$. When the rotating speed reaches $962 \mathrm{rad} / \mathrm{s}$, the system undergoes an inverse period doubling bifurcation and leaves 
chaotic motion. At $\omega=1192 \mathrm{rad} / \mathrm{s}$, the system becomes quasi-periodic motion from periodic- 2 motion and keeps periodic-3 motion at $1663 \mathrm{rad} / \mathrm{s}<\omega<1991 \mathrm{rad} / \mathrm{s}$ with the increase of rotating speed. As indicated from Figure 15d, the system bifurcates into periodic- 2 motion at $\omega=826 \mathrm{rad} / \mathrm{s}$ and leaves chaotic motion at $\omega=948 \mathrm{rad} / \mathrm{s}$. The system presents similar characteristics with the increase of rotating speed compared with $\delta_{0}=0.03 \mathrm{~mm}$.

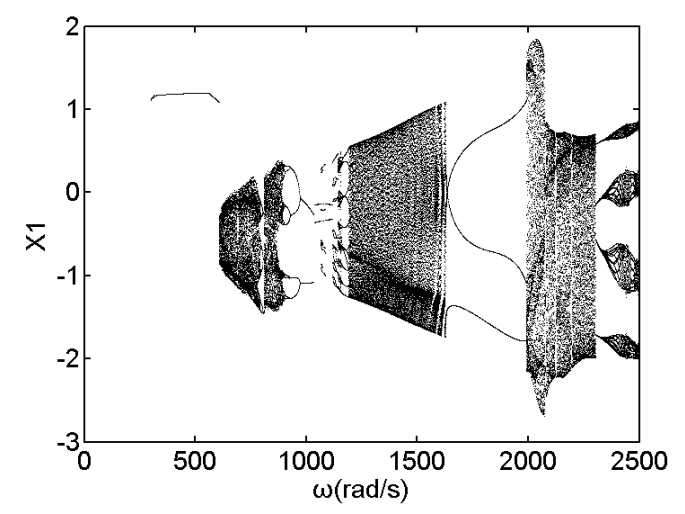

(a)

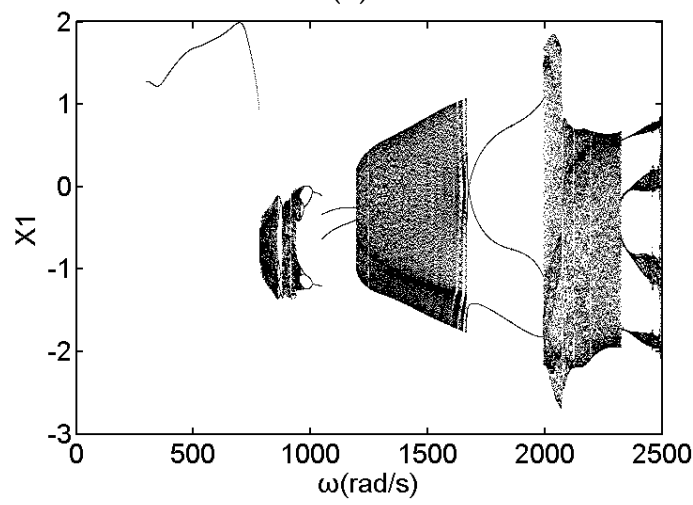

(c)

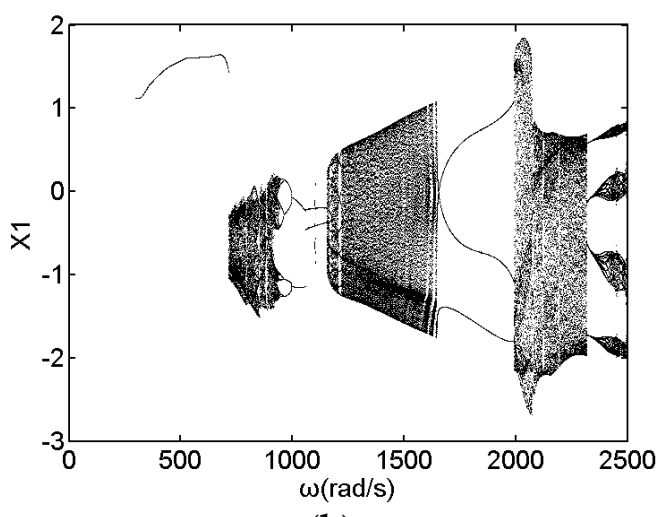

(b)

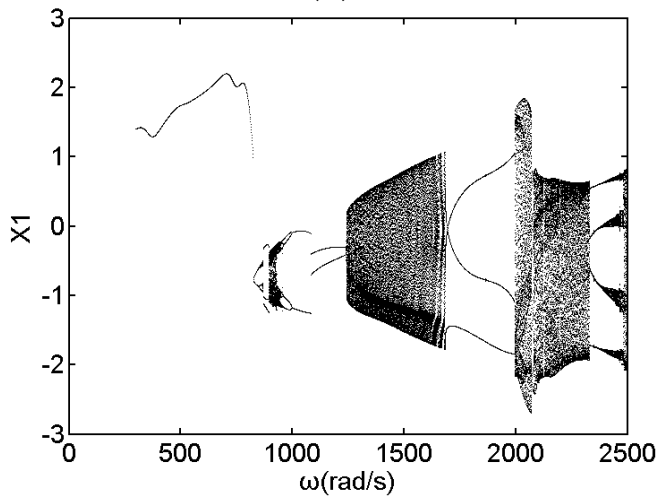

(d)

Figure 15. Bifurcation diagram of disk 1 center in a horizontal direction at $k_{c}=1 \times 10^{7} \mathrm{~N} / \mathrm{m}$. (a) $\delta_{0}=0.01 \mathrm{~mm}$; (b) $\delta_{0}=0.02 \mathrm{~mm}$; (c) $\delta_{0}=0.03 \mathrm{~mm}$; (d) $\delta_{0}=0.04 \mathrm{~mm}$.

It can be seen from Figure 15 that the system bifurcation diagrams under different initial permanent deflection length $\delta_{0}$ do not present an obvious differences in high-speed regions. In a low-speed region, the system keeps periodic- 1 motion under different initial permanent deflection lengths. The instability speed of the system gradually rises with the increase of initial permanent deflection length. Meanwhile, the chaotic motion region becomes smaller and smaller. Although the instability speed of the system increased with the value of initial permanent deflection length $\delta_{0}$, the initial permanent deflection is not expected.

\subsection{Effect of Radial Stiffness of the Stator}

Radial stiffness of the stator is an important factor of a rub-impact rotor bearing system. In this part, the influence of radial stiffness of the stator is discussed under certain conditions. Taking radial stiffness of the stator as the control parameter, Figure 16 shows the bifurcation diagram of disk 1 center in a horizontal direction at $\omega=826 \mathrm{rad} / \mathrm{s}, r_{0}=0.11 \mathrm{~mm}, \delta_{0}=0.01 \mathrm{~mm}$. 


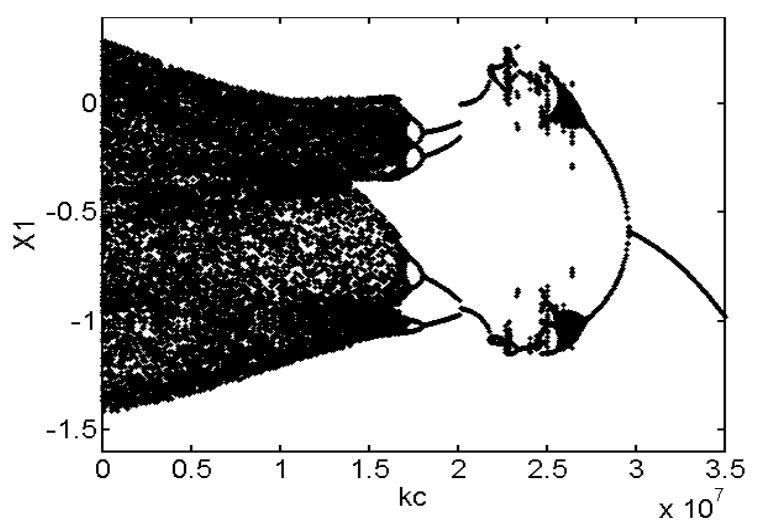

Figure 16. Bifurcation diagram of disk 1 center in a horizontal direction.

It can be seen from Figure 16 that the system states vary with the increase of the radial stiffness of the stator. When the stiffness is small, the rub-impact force is far less than oil-film force, and the system response is mainly decided by the oil-film force and initial permanent deflection. The system presents chaotic motion at $k_{c}=\left[0-1.71 \times 10^{7}\right] \mathrm{N} / \mathrm{m}$. As shown in Figure 17, the orbit is irregular, the Poincaré map presents a strange attractor, and the frequency spectrum contains continuous frequency bands. Meanwhile, there is a half fundamental frequency component in the frequency spectrum, and oil whirl occurs at this condition. With the increase of radial stiffness of stator $k_{c}$, the system experiences periodic- 8 motion, periodic -4 motion, and periodic- 2 motion. Figure 18 shows the periodic-4 motion at $k_{c}=1.9 \times 10^{7} \mathrm{~N} / \mathrm{m}$, and there are four isolated points in Poincaré map. At $k_{c}=\left[2.19 \times 10^{7}-2.73 \times 10^{7}\right] \mathrm{N} / \mathrm{m}$, the system undergoes multi-periodic motions and returns back to periodic-2 motion at $k_{c}=2.73 \times 10^{7} \mathrm{~N} / \mathrm{m}$ (see in Figure 19). When $k_{c}>2.97 \times 10^{7} \mathrm{~N} / \mathrm{m}$, the system displays a synchronous periodic- 1 motion, and the oil whirl disappears under this condition (see in Figure 20).

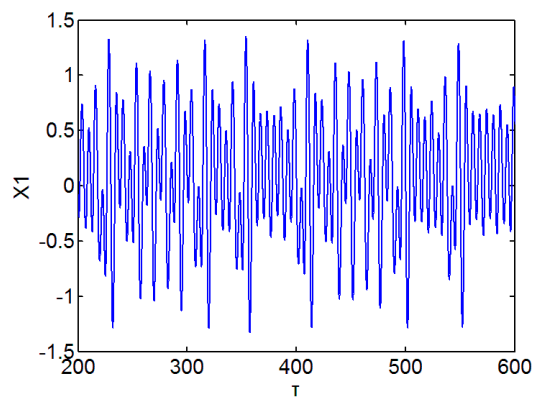

(a)

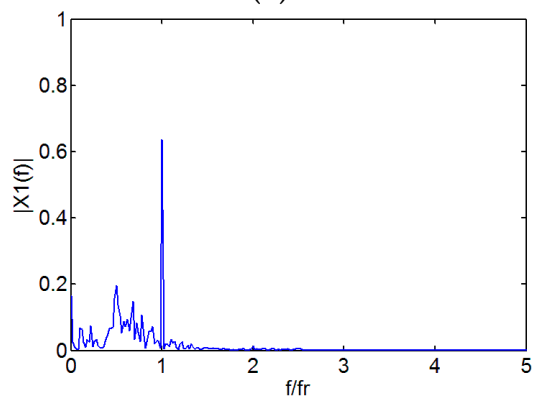

(c)

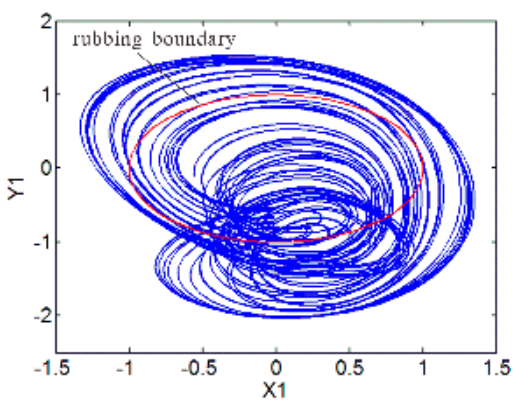

(b)

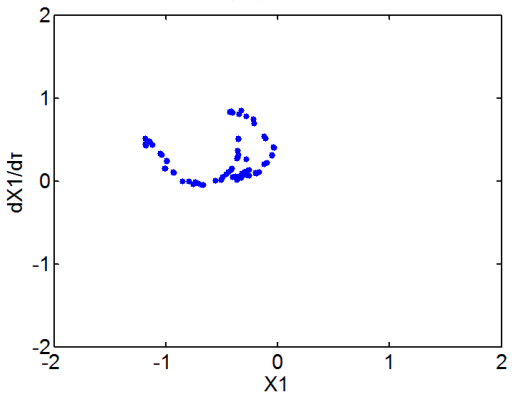

(d)

Figure 17. Numerical analysis results at $k_{c}=1.2 \times 10^{7} \mathrm{~N} / \mathrm{m}$. (a) Time domain waveform; (b) Shaft orbit; (c) Frequency spectrum; (d) Poincaré map. 


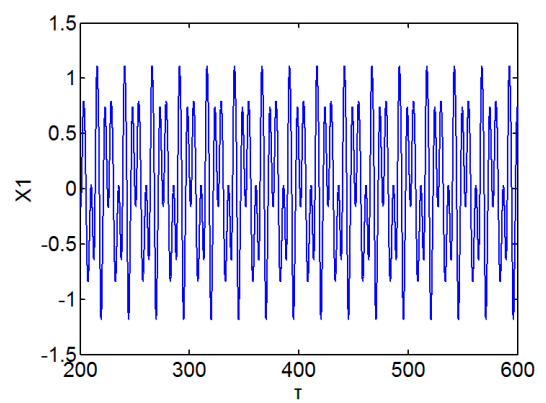

(a)

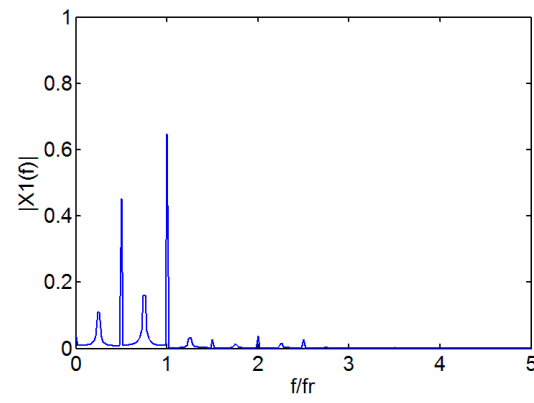

(c)

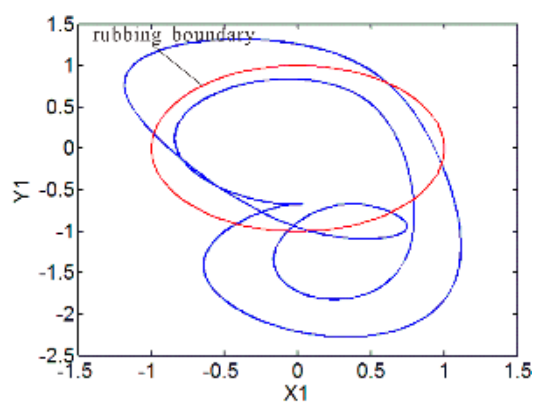

(b)

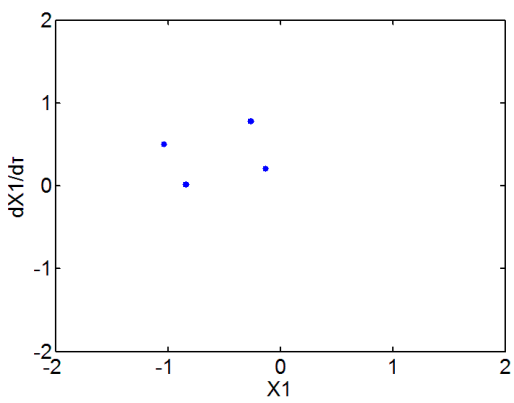

(d)

Figure 18. Numerical analysis results at $k_{c}=1.9 \times 10^{7} \mathrm{~N} / \mathrm{m}$. (a) Time domain waveform; (b) Shaft orbit; (c) Frequency spectrum; (d) Poincaré map.

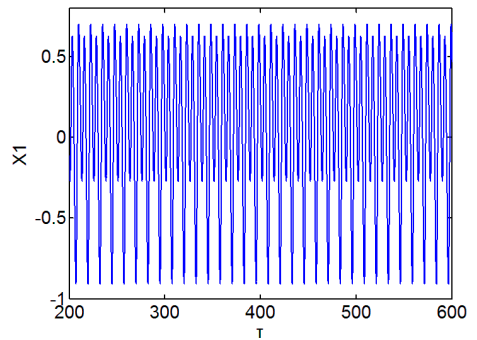

(a)

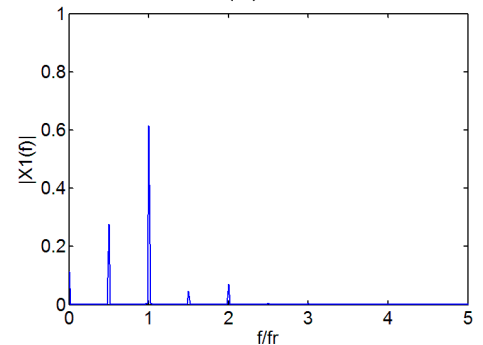

(c)

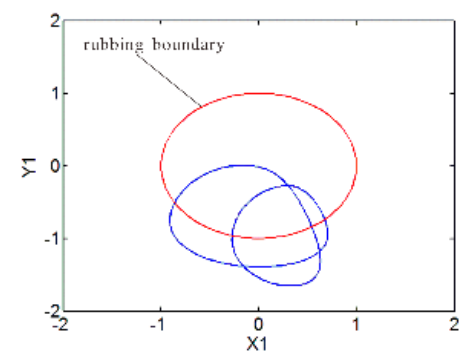

(b)

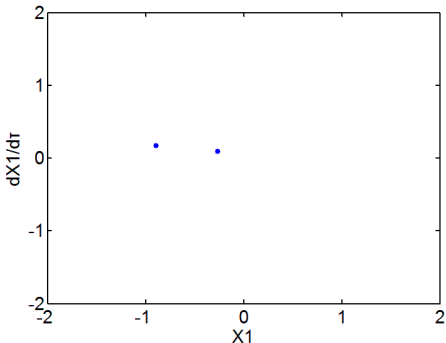

(d)

Figure 19. Numerical analysis results at $k_{c}=2.85 \times 10^{7} \mathrm{~N} / \mathrm{m}$. (a) Time domain waveform; (b) Shaft orbit; (c) Frequency spectrum; (d) Poincaré map.

The radial stiffness of the stator has a great influence on the responses of a rub-impact rod fastening rotor bearing system under initial permanent deflection. With the increase of radial stiffness for the stator, the system response becomes simpler under certain conditions. Meanwhile, the oil whirl is weaker or even disappears at a certain rotating speed. 


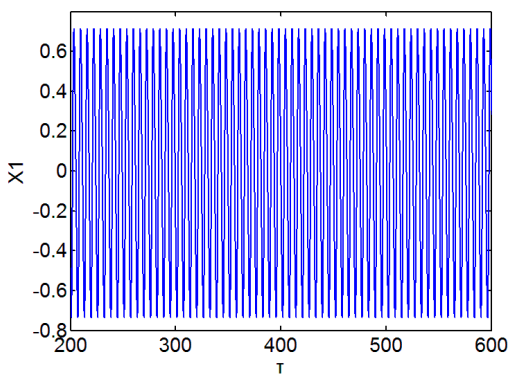

(a)

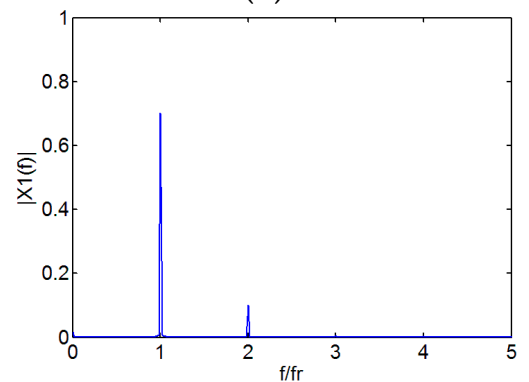

(c)

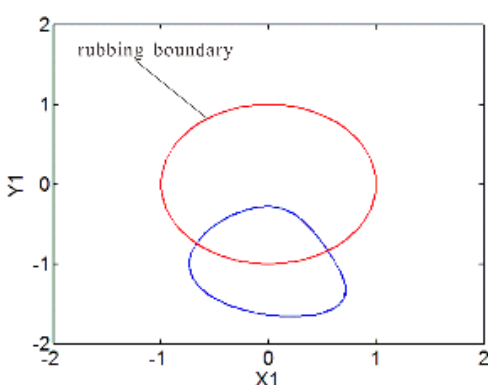

(b)

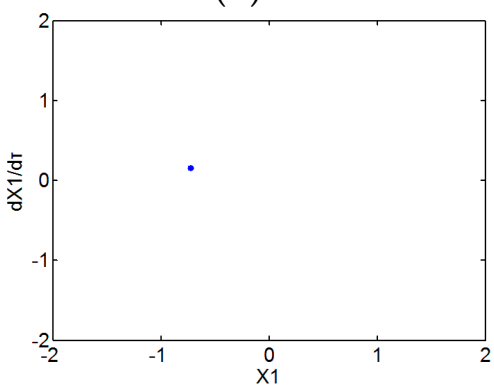

(d)

Figure 20. Numerical analysis results at $k_{c}=3.2 \times 10^{7} \mathrm{~N} / \mathrm{m}$. (a) Time domain waveform; (b) Shaft orbit; (c) Frequency spectrum; (d) Poincaré map.

\section{Conclusions}

The dynamic motion equations of a rod fastening rotor bearing system under rub-impact and initial permanent deflection is derived based on the D'Alembert principle. The coupled nonlinear dynamic characteristics of the rod fastening rotor bearing system under rub-impact and initial permanent deflection have been investigated. The effect of radial stiffness for the stator, initial permanent deflection length and rotating speed on the dynamic characteristics of the rod fastening rotor bearing system are investigated in detail. The following conclusions can be obtained from the above analysis:

1 The dynamic responses of the rod fastening rotor bearing system under rub-impact and initial permanent deflection exhibit a rich nonlinear dynamic diversity, synchronous periodic- 1 motion, multi-periodic motion, chaotic motion and quasi-periodic motion can be observed through the analysis.

2 Initial permanent deflection length has a great effect on the dynamic response of the system in the low-speed regions. With the increase of initial permanent deflection length, the instability speed of the system gradually rises, and the chaotic motion region becomes smaller and smaller.

3 With the increase of radial stiffness of the stator, the system response becomes simpler under certain conditions. Meanwhile, the oil whirl is weaker or even disappears at a certain rotating speed.

4 It is unsuitable to take the rod fastening rotor as an integral rotor in analyzing the coupled nonlinear dynamic responses of the system under rub-impact and initial permanent deflection.

The corresponding results can provide the guidance for the fault diagnosis of a rub-impact rod fastening rotor and contribute to the further understanding of the nonlinear dynamic characteristics of a rub-impact rod fastening rotor.

Acknowledgments: This work is supported by the Research Funds for the Central Universities Achievement Transformation in Beijing (No. ZDZH20141005401), the National Natural Science Foundation of China (No. 51575180) and the Fundamental Research Funds for the Central Universities (No. 2015XS79). 
Author Contributions: Liang $\mathrm{Hu}$ and Yibing Liu modeled governing motion equations of the rod fastening rotor under rub-impact and initial permanent deflection; Wei Teng designed the Matlab program; Chao Zhou contributed analysis tools; Liang Hu wrote the paper.

Conflicts of Interest: The authors declare no conflict of interest.

\section{Symbols}

\begin{tabular}{|c|c|}
\hline$c$ & Radial clearance of bearing \\
\hline$\mu$ & Oil viscosity \\
\hline$L$ & Bearing length \\
\hline$R$ & Bearing radius \\
\hline$\delta$ & Sommerfeld correction coefficient \\
\hline$h$ & Thickness of oil-film \\
\hline$p$ & Dimensionless pressure of oil-film \\
\hline$F_{x}, F_{y}$ & Nonlinear oil-film force in $x$-direction and $y$-direction \\
\hline$f_{x}, f_{y}$ & Dimensionless nonlinear film force in $x$-direction and $y$-direction \\
\hline$P_{T}, P_{N}$ & Rub-impact force in radial and tangential direction \\
\hline$P_{x}, P_{y}$ & Rub-impact in $x$-direction and $y$-direction \\
\hline$\eta$ & Friction coefficient \\
\hline$r_{0}$ & Initial clearance \\
\hline$\delta_{0}$ & Initial permanent deflection \\
\hline$k_{c}$ & Radial stiffness of the stator \\
\hline$F_{c x}, F_{c y}$ & Restoring force of contact layer in $x$-direction and $y$-direction \\
\hline$m_{\mathrm{b} 1}, m_{\mathrm{b} 2}$ & Lumped mass of bearings \\
\hline$m_{1}, m_{2}$ & Lumped mass of disks \\
\hline$e_{1}, e_{2}$ & Eccentric distance of disks \\
\hline$\phi$ & Angle between mass eccentricity of the two disks \\
\hline$\beta$ & Angle between mass eccentricity and initial permanent deflection \\
\hline$k$ & Shaft stiffness \\
\hline$k_{1}$ & Linear contact stiffness \\
\hline$k_{1}^{\prime}$ & Nonlinear contact stiffness \\
\hline$c_{1}$ & Damping of bearing \\
\hline$c_{2}$ & Damping of disk \\
\hline$c_{3}$ & Damping of contact layer \\
\hline$x_{i}, y_{i}(i=1,2)$ & Displacements of disks in $x$-direction and $y$-direction \\
\hline$x_{b i}, y_{b i}(i=1,2)$ & Displacements of bearings in $x$-direction and $y$-direction \\
\hline$X_{i}, Y_{i}(i=1,2)$ & Dimensionless displacements of disks in $x$-direction and $y$-direction \\
\hline$X_{b i}, Y_{b i}(i=1,2)$ & Dimensionless displacements of bearings in $x$-direction and $y$-direction \\
\hline$\omega$ & Rotating speed \\
\hline$g$ & Gravitational acceleration \\
\hline
\end{tabular}

\section{References}

1. Muszynska, A. Rotor-to-stationary element rub-related vibration phenomenon in rotating machinery-Literature survey. Shock Vib. Dig. 1989, 21, 3-11. [CrossRef]

2. Ma, H.; Zhao, Q.B.; Zhao, X.Y.; Han, Q.K.; Wen, B.C. Dynamic characteristics analysis of a rotor-stator system under different rubbing forms. Appl. Math. Model. 2015, 39, 2392-2408. [CrossRef]

3. Ma, H.; Yin, F.L.; Wu, Z.Y.; Tai, X.Y.; Wen, B.C. Nonlinear vibration response analysis of a rotor-blade system with blade-tip rubbing. Nonlinear Dyn. 2015, 84, 1225-1258. [CrossRef]

4. Ma, H.; Yu, T.; Han, Q.K.; Zhang, Y.M.; Wen, B.C.; Chen, X.L. Time-frequency features of two types of coupled rub-impact faults in rotor systems. J. Sound Vib. 2009, 321, 1109-1128. [CrossRef] 
5. Weaver, B.K.; Zhang, Y.; Clarens, A.F.; Untaroiu, A. Nonlinear Analysis of Rub Impact in a Three-Disk Rotor and Correction Via Bearing and Lubricant Adjustment. J. Eng. Gas Turbines Power 2015, 137, 092504. [CrossRef]

6. Goldman, P.; Muszynska, A. Chaotic behavior of rotor-stator systems with rubs. J. Eng. Gas Turbines Power 1994, 116, 692-701. [CrossRef]

7. Xiang, L.; Hu, A.J.; Hou, L.L.; Xiong, Y.P.; Xing, J.T. Nonlinear coupled dynamics of an asymmetric double-disc rotor-bearing system under rub-impact and oil-film forces. Appl. Math. Model. 2016, 40, 4505-4523. [CrossRef]

8. Wang, C.; Zhang, D.Y.; Ma, Y.H.; Liang, Z.C.; Hong, J. Theoretical and experimental investigation on the sudden unbalance and rub-impact in rotor system caused by blade off. Mech. Syst. Signal Process. 2016, 76, 111-135. [CrossRef]

9. Varney, P.; Green, I. Nonlinear phenomena, bifurcations, and routes to chaos in an asymmetrically supported rotor-stator contact system. J. Sound Vib. 2015, 336, 207-226. [CrossRef]

10. Tai, X.Y.; Ma, H.; Liu, F.H.; Liu, Y.; Wen, B.C. Stability and steady-state response analysis of a single rub-impact rotor system. Arch. Appl. Mech. 2014, 85, 133-148. [CrossRef]

11. Nembhard, A.D.; Sinha, J.K.; Yunusa-Kaltungo, A. Experimental observations in the shaft orbits of relatively flexible machines with different rotor related faults. Measurement 2015, 75, 320-337. [CrossRef]

12. Yunusa-Kaltungo, A.; Nembhard, A.D.; Sinha, J.K. Experimental Observations of Rotor Orbit Analysis in Rotating Machines; Springer: Berlin, Germany, 2015; Volume 21, pp. 1551-1560.

13. Edwards, S.; Lees, A.W.; Friswell, M.I. The influence of torsion on rotor-stator contact in rotating machinery. J. Sound Vib. 1999, 225, 767-778. [CrossRef]

14. Sun, Z.C.; Xu, J.X.; Zhou, T.; Tan, N. Study on influence of bending-torsion coupling in an impacting-rub rotor system. Appl. Math. Mech. 2003, 24, 1316-1323.

15. Khanlo, H.M.; Ghayour, M.; Ziaei-Rad, S. The effects of lateral-torsional coupling on the nonlinear dynamic behavior of a rotating continuous flexible shaft-disk system with rub-impact. Commun. Nonlinear Sci. Numer. Simul. 2013, 18, 1524-1538. [CrossRef]

16. Patel, T.H.; Darpe, A.K. Coupled bending-torsional vibration analysis of rotor with rub and crack. J. Sound Vib. 2009, 326, 740-752. [CrossRef]

17. Yuan, Z.W.; Chu, F.L.; Hao, R.J. Simulation of rotor's axial rub-impact in full degrees of freedom. Mech. Mach. Theory 2007, 42, 763-775. [CrossRef]

18. Nicholas, J.C.; Gunter, E.J.; Allaire, P.E. Effect of residual shaft bow on unbalance response and balancing of a single mass flexible rotor. J. Eng. Power-Trans. ASME 1976, 98, 171-189. [CrossRef]

19. Song, G.F.; Yang, Z.J.; Ji, C.; Wang, F.P. Theoretical-experimental study on a rotor with a residual shaft bow. Mech. Mach. Theory 2013, 63, 50-58. [CrossRef]

20. Darpe, A.K.; Gupta, K.; Chawla, A. Dynamics of a bowed rotor with a transverse surface crack. J. Sound Vib. 2006, 296, 888-907. [CrossRef]

21. Flack, R.D.; Rooke, J.H. A theoretical-experimental comparison of the synchronous response of a bowed rotor in five different sets of fluid film bearings. J. Sound Vib. 1980, 73, 507-517. [CrossRef]

22. He, P.; Liu, Z.H.; Huang, F.L.; Liu, Z.X. Experimental Study of the Variation of Tie-bolt Fastened Rotor Critical Speeds with Tighten Force. J. Sound Vib. Meas. Diagn. 2014, 34, 644-649. (In Chinese)

23. Yuan, Q.; Gao, J.; Li, P. Nonlinear Dynamics of the Rod-Fastened Jeffcott Rotor. J. Vib. Acoust. 2014, 136, 1-10. [CrossRef]

24. Mat Isa, A.A.; Penny, J.E.T.; Garvey, S.D. Dynamics of bolted and laminated rotors. In Proceedings of the 18th IMAC Conference on Computational Challenges in Structural Dynamics, San Antonio, TX, USA, 7-10 February 2000.

25. Hei, D.; Lu, Y.J.; Zhang, Y.F.; Liu, F.X.; Zhou, C.; Müller, N. Nonlinear dynamic behaviors of rod fastening rotor-hydrodynamic journal bearing system. Arch. Appl. Mech. 2015, 85, 855-875. [CrossRef]

26. Hei, D.; Lu, Y.J.; Zhang, Y.F.; Lu, Z.Y.; Gupta, P.; Müller, N. Nonlinear dynamic behaviors of a rod fastening rotor supported by fixed-tilting pad journal bearings. Chaos Solitons Fractals 2014, 69, 129-150. [CrossRef] 
27. Cheng, L.; Qian, Z.W.; Chen, W.; Fan, J.D. Influence of Structural Parameters on the Bistable Response of a Disk-Rod-Fastening Rotor. J. Sound Vib. Meas. Diagn. 2012, 32, 767-772. (In Chinese)

28. Qian, Z.W.; Cheng, L.; Chen, W.; Li, Y.H. Analysis on bistable response of a disk-rod-fastening rotor. J. Aerosp. Power. 2011, 26, 1563-1568. (In Chinese)

29. Capone, G. Analytical Description of Fluid-dynamic Force Field in Cylindrical Journal Bearing. L'Energia Elettr. 1991, 3, 105-110.

30. Adiletta, G.; Guido, A.R.; Rossi, C. Chaotic Motions of a Rigid Rotor in Short Journal Bearings. Nonlinear Dyn. 1996, 10, 251-269. [CrossRef]

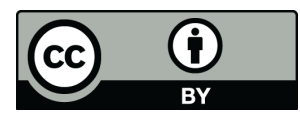

(c) 2016 by the authors; licensee MDPI, Basel, Switzerland. This article is an open access article distributed under the terms and conditions of the Creative Commons Attribution (CC-BY) license (http://creativecommons.org/licenses/by/4.0/). 